\title{
ANÁLISE DA ADEQUAÇÃO DO PROJETO PEDAGÓGICO DO CURSO DE ENGENHARIA ELÉTRICA FRENTE AS NOVAS DIRETRIZES CURRICULARES DE ENGENHARIA
}

DOI: 10.37702/2175-957X.COBENGE.2021.3399

Marcos Jolbert Cáceres Azambuja - marcosjolbert@gmail.com

Universidade de Sao Paulo

Rua Gabriela 225

12630-000 - Cachoeira Paulista - SP

Jose Aquiles Baesso Grimoni - jose.grimoni@usp.br

Universidade de Sao Paulo

Rua Pereira do Lago - 360158

05590-000 - Sao Paulo - SP

Resumo: Este artigo apresenta uma análise do projeto pedagógico do curso de engenharia elétrica com ênfase em energia e automação elétricas em relação as novas diretrizes curriculares de engenharia aprovadas em abril de 2019. A análise foi feita comparando os itens mínimos propostos nas diretrizes e os itens propostos no projeto pedagógico do curso de maneira crítica visando detectar pontos atendidos e pontos incompletos e que necessitam uma revisão e readequação. As novas diretrizes promulgadas pelo Ministério de Educação - MEC, como as de 2002, são centradas no desenvolvimento de competências e exigem que os projetos pedagógicos explicitem como elas são desenvolvidas e reforçadas e como são avaliadas durante o curso nas disciplinas. Há um forte incentivo ao uso de novas situações de ensino e aprendizagem e o uso de ambientes adequados que privilegiem estratégias ativas, onde os alunos são o centro do processo. A maior interação da universidade com a sociedade e seus diversos agentes, como o governo nas suas várias instâncias, com as empresas, ONGs e' incentivada no oferecimento de estágios e na proposta de trazer os problemas do mundo real para debate e busca de soluções. O número mínimo de horas de estágio de 180 horas foi mantido e a exigência de um projeto final de curso também foi mantida nestas novas diretrizes. Como conclusão do trabalho são discutidas propostas de alteração no projeto pedagógico do curso para adequá-lo as novas diretrizes do curso de engenharia. 


\section{COBENGE

Palavras-chave: Projeto Pedagógico de Curso, Diretrizes Curriculares Nacionais, Engenharia, Ensino baseado em competências. 


\section{INTRODUÇÃO}

A relevância em debater a estrutura curricular dos cursos de engenharia no país dá a oportunidade de refletir como está a expectativa da comunidade acadêmica, empresas e dos setores onde o profissional recém-formado irá atuar visando as demandas futuras por mais e melhores engenheiros.

"O capital humano, sem dúvida, é um dos fatores críticos para o desenvolvimento econômico e social, [...] é fundamental buscar a melhoria constante da formação e qualificação dos recursos humanos disponíveis". (MEC, 2019).

A engenharia ocupa um lugar importante na geração de conhecimento, tecnologias e inovações. Desta forma, é preciso considerar que os cursos precisam de uma reformulação, que ensinem os alunos a terem habilidades em liderança, trabalharem em grupo, habilidades em planejamento e gestão estratégica, autonomia do conhecimento e com formação humanista e empreendedora.

Tendo em vista este lugar central da engenharia, faz-se necessário uma análise minuciosa dos projetos pedagógicos de curso e suas estruturas curriculares.

Este artigo tem como objetivo analisar o Projeto Pedagógico de Curso - PPC, da Habilitação em Engenharia Elétrica com ênfase em Energia e Automação da Escola Politécnica da Universidade de São Paulo - EPUSP, com base na estrutura curricular de 2016, em relação as propostas apresentadas nas Novas Diretrizes Curriculares Nacionais do Curso de Graduação em Engenharia, aprovadas Conselho Nacional de Educação - CNE e a Câmara de Educação Superior - CES e pelo MEC agora em 23 de abril de 2019, e dar ênfase em propostas de melhorias no curso de engenharia elétrica.

Nas considerações finais são pontuadas novas reflexões acerca dos projetos pedagógicos da engenharia elétrica da EPUSP.

\section{UM BREVE HISTÓRICO DA EPUSP}

De acordo com o PPC da EPUSP, conforme PEA (2016), a escola foi fundada em 1893 e as primeiras turmas iniciaram os cursos em 1894, contando com 31 alunos regulares e 28 ouvintes matriculados nos quatro cursos oferecidos: Engenharia Civil, Industrial, Agrícola e curso anexo de Artes Mecânicas.

A escola surgiu, portanto, num momento fundamental da vida de São Paulo. Foi um dos pilares de implantação da indústria e, mais tarde, propulsora do processo de modernização tecnológica, intervindo diretamente na vida econômica do Estado e contribuindo para transformá-lo no principal centro econômico do País.

A Universidade de São Paulo foi criada em 1934 num contexto marcado por importantes transformações sociais, políticas e culturais, pelo decreto estadual nํ.6.283, de 25 de janeiro de 1934, por decisão do governador de São Paulo, Armando de Salles Oliveira. A Escola Politécnica foi incorporada à USP nesta data e foi uma das unidades co-fundadoras.

Criada em 1893, conta hoje com uma área edificada de $141.500 \mathrm{~m}^{2}, 15$ departamentos, 103 laboratórios e com um total de 457 docentes e carca de 5000 alunos de graduação além de programas de pós-graduação, de pesquisa e de extensão.

A Escola Politécnica da USP tem como missão preparar profissionais competentes para liderar o desenvolvimento tecnológico do Estado de São Paulo e do Brasil, 
proporcionando com isso a melhoria da qualidade de vida da sociedade. Sua visão: ser uma escola de engenharia líder e reconhecida como referência a nível mundial.

\subsection{Plano Pedagógico de Curso da EPUSP}

Com base no PPC, conforme PEA (2016), os objetivos da EPUSP são: sistematização do saber historicamente acumulado pela humanidade, construção de novos conhecimentos e sua disseminação; formação dos agentes e profissionais necessários à sociedade, nas diferentes habilitações da engenharia, competentes em sua respectiva especialidade; desenvolvimento integral do estudante, de maneira que compreenda e pense de forma analítica e crítica os diferentes fenômenos de ordem humana, natural e social; e a graduação como etapa inicial formal, que constrói a base para o permanente e necessário processo de educação continuada.

Os cursos de Engenharia da EPUSP foram planejados a partir de conceitos que deveriam garantir a formação do seguinte perfil dos egressos: adequada formação científica; sólida formação em técnicas da engenharia; capacidade de interpretação, análise e crítica das organizações; preparo para enfrentar situações novas, com iniciativa e criatividade; capacidade de buscar e gerar conhecimento tecnológico e metodológico; consciência e preparo para ser um agente da evolução econômica e social; e consciência para desenvolver uma conduta profissional ética.

Para atender ao perfil definido para o egresso - o futuro engenheiro, os currículos das diversas habilitações da EPUSP estão planejados para levar ao desenvolvimento integral do aluno. $O$ engenheiro formado deve ter sido estimulado a desenvolver um perfil profissional caracterizado por competências e habilidades a seguir descritas:

a) Ter capacidade de conceber e analisar sistemas, produtos e processos.

b) Ter capacidade de operar e manter sistemas.

c) Ter capacidade de planejar e ser objetivo no estabelecimento de metas, de elaborar soluções técnica e economicamente competitivas, de supervisionar e de coordenar projetos de Engenharia.

d) Ter visão crítica de ordem de grandeza na solução e interpretação de resultados de engenharia.

e) Ter capacidade de liderança para trabalhar em equipe.

f) Ter iniciativa e criatividade para tomada de decisões.

g) Ter visão clara do papel de cliente, produtor, fornecedor e consumidor.

h) Saber bem usar as ferramentas básicas da informática.

i) Ter a capacidade de comunicar oralmente e de registrar, de forma ética, seu conhecimento, tanto em português como em pelo menos uma língua estrangeira, preferencialmente o inglês.

Os currículos devem estar organizados para também desenvolver no estudante um senso crítico e de cidadania que o possibilite a ter as seguintes atitudes no exercício profissional:

- Compromisso com a qualidade do que faz;

- Compromisso com a ética profissional;

- Responsabilidade social, política e ambiental;

- Postura proativa e empreendedora; e

- Compreensão da necessidade da permanente busca de atualização profissional. 


\subsection{Proposta pedagógica do PEA - USP}

A proposta pedagógica conforme PPC, conforme PEA (2016) visa formar um profissional que apresente forte embasamento conceitual tanto em sua formação geral de Engenheiro Eletricista, como em sua formação profissionalizante.

A proposta se apoia nas disciplinas básicas dos primeiros anos tais como: Circuitos Elétricos, Eletrônica, Projeto Lógico Digital, Eletromagnetismo e Conversão Eletromecânica de Energia. A estrutura apresenta ainda uma sequência de disciplinas de objetivo profissionalizante, que foram agrupadas em seis conjuntos de disciplinas:

- Sistemas Elétricos de Potência;

- Automação de Sistemas Elétricos;

- Energia Elétrica;

- Instalações Elétricas;

- Máquinas Elétricas; e

- Eletrônica de Potência.

Os quatro primeiros conjuntos contemplam uma análise sistêmica de um sistema de energia elétrica, ao passo que os dois últimos conjuntos são relacionados ao funcionamento de seus equipamentos típicos.

\subsection{Objetivos e perfil do egresso do PEA}

O objetivo do curso apontado no PPC, conforme PEA (2016) é preparar engenheiros que atuem não só no planejamento e concepção de processos industriais específicos, mas também em atividades sistêmicas relacionadas a projetos multidisciplinares de engenharia que envolvam soluções energéticas. A estratégia pedagógica está balanceada em exposições teóricas, aulas experimentais de laboratório, estudos de caso e execução de projetos, possibilitando uma formação sólida e abrangente nas áreas de energia, automação, equipamentos e máquinas elétricas, sistemas de potência e eletrônica de potência, permitindo uma atuação profissional em toda a cadeia energética de geração, transmissão, distribuição e uso de energia.

A finalidade desta formação abrangente, apoiada em fundamentos científicos clássicos e métodos modernos de modelagem, análise e síntese, é permitir ao engenheiro amplas possibilidades de atuação na engenharia elétrica e concepção de soluções inovadoras no âmbito dos problemas do setor produtivo e da sociedade como um todo, dando contribuição significativa e exercendo papel de liderança nos desafios profissionais e agregando conhecimento na área de energia elétrica.

O perfil desejado do profissional a ser formado, conforme PEA (2016), é descrito em suas diretrizes, pois muitas dessas habilidades e posturas não constam explicitamente nos conteúdos curriculares, mas devem ser desenvolvidas implicitamente nas atividades realizadas no decorrer do curso, incluindo as não-curriculares e várias delas somente sedimentam-se ao longo do tempo, inclusive após o término formal do curso.

Uma lista deve ser incluída para obter as seguintes habilidades e posturas:

- Forte embasamento conceitual nas áreas básicas científicas, matemáticas e de engenharia;

- Sólida formação tecnológica e científica que o capacite a absorver e gerar conhecimento tecnológico e metodológico;

- Compromisso com o aprendizado contínuo;

- Postura proativa e criativa; 
- Postura ética e humanística profissional e pessoal;

- Adaptabilidade para atuar em situações novas com iniciativa e criatividade;

- Habilidade para organizar, planejar e se expressar (de forma gráfica, oral e escrita);

- Capacidade de trabalhar integrado a um grupo, incluindo sociabilidade e motivação de parceiros;

- Capacidade de liderança para trabalhos em equipe;

- Capacidade para o empreendedorismo, ou seja, de assumir riscos calculados na criação, formulação, planejamento e implementação de inovações;

- Visão sistêmica e multidisciplinar da engenharia, em contraponto a uma visão fragmentada e restrita;

- Capacidade para buscar, selecionar e interpretar criticamente informações para a solução de problemas;

- Resolução de problemas de engenharia considerando os seus aspectos políticos, econômicos, sociais, ambientais e culturais; e

- Capacidade de articular e implementar soluções otimizadas quanto a custos, complexidade, acessibilidade, manutenção, bem como a execução da solução em si e a manutenção de seus resultados.

\subsection{Habilidades e Competências do PEA da EPUSP}

As habilidades e competências perseguidas pela formação no curso de Engenharia Elétrica da EPUSP, tem por objetivo dotar o profissional nos seguintes conhecimentos requeridos conforme PEA (2016):

- Aplicar conhecimentos matemáticos, científicos, tecnológicos e instrumentais à engenharia;

- Projetar e conduzir experimentos e interpretar resultados;

- Conceber, projetar e analisar sistemas, produtos e processos;

- Planejar, supervisionar, elaborar e coordenar projetos e serviços de engenharia;

- Identificar, formular e resolver problemas de engenharia;

- Desenvolver e/ou utilizar novas ferramentas e técnicas;

- Supervisionar a operação e a manutenção de sistemas;

- Avaliar criticamente a operação e a manutenção de sistemas;

- Comunicar-se eficientemente nas formas escrita, oral e gráfica;

- Atuar em equipes multidisciplinares;

- Compreender e aplicar a ética e responsabilidade profissionais;

- Avaliar o impacto das atividades da engenharia no contexto social e ambiental;

- Avaliar a viabilidade econômica de projetos de engenharia;

- Assumir a postura de permanente busca de atualização profissional.

\section{DCNs DO CURSO DE GRADUAÇÃO EM ENGENHARIA}

O texto a seguir, extraído das DCN, define bem o que são as diretrizes curriculares nacionais de engenharia: 
"As diretrizes (guideline) são normas que orientam o projeto e o planejamento de um curso de graduação. Disso depreende-se que as diretrizes nacionais curriculares devem encerrar necessariamente certa flexibilidade para se adequar aos diversos contextos espaciais e temporais, sem tolher, no entanto, a melhoria contínua ou a inserção de inovações decorrentes, por exemplo, de novas tecnologias e metodologias. Ao contrário, as diretrizes nacionais curriculares devem servir de incentivo a essas ações inovadoras". (MEC, 2019, p. 2).

Diante das transformações profundas que na atualidade estão acontecendo na produção e no trabalho conforme apontado na DCN de Engenharia:

"As DCNs devem ser capazes de estimular a modernização dos cursos de Engenharia, mediante a atualização contínua, o centramento no estudante como agente de conhecimento, a maior integração empresa-escola, a valorização da inter e da transdisciplinaridade, assim como do importante papel do professor como agente condutor das mudanças necessárias, dentro e fora da sala de aula". (BRASIL, 2019, p. 2).

É esperado um perfil de engenheiro mais diversificado, por exemplo: Pesquisador, empreendedor ou mais ligado às operações.

As DCNs anteriores já traziam em seu contexto essas preocupações:

"O novo engenheiro deve ser capaz de propor soluções que sejam não apenas tecnicamente corretas, ele deve ter a ambição de considerar os problemas em sua totalidade, em sua inserção numa cadeia de causas e efeitos de múltiplas dimensões. Não se adequar a esse cenário procurando formar profissionais com tal perfil significa atraso no processo de desenvolvimento". (MEC, 2002, p. 1). revisão:

As novas DCNs de Engenharia (2019) apontam as seguintes premissas para uma

"(i) elevar a qualidade do ensino em Engenharia no país; (ii) permitir maior flexibilidade na estruturação dos cursos de Engenharia, para facilitar que as instituições de ensino inovem seus modelos de formação; (iii) reduzir a taxa de evasão nos cursos de Engenharia, com a melhoria de qualidade; e (iv) oferecer atividades compatíveis com as demandas futuras por mais e melhores formação dos engenheiros." (BRASIL, 2019, p. 2).

Com base nas DCNs de Engenharia do ano de 2019 é possível verificar o perfil do egresso e as competências esperadas considerando o cenário nacional e mundial, dada a globalização da área da engenharia.

\subsection{Perfil do egresso e competências esperadas pelas DCNs de Engenharia}

A primeira atitude esperada pelas DCNs de Engenharia, para a implantação de um novo curso é verificar a necessidade no contexto em que a IES se insere. Após a verificação da necessidade faz-se necessário estabelecer o perfil do egresso, "que deve se voltar para uma visão sistêmica e holística de formação, não só do profissional, mas também do 
cidadão-engenheiro, de tal modo que se comprometa com os valores fundamentais da sociedade na qual se insere". (MEC, 2019, p. 25).

As DCNs de Engenharia (2019) apontam que o PPC da IES, deve estabelecer as atividades que acentuem esse perfil, para formar profissionais comprometidos com a cidadania de uma maneira geral.

Assim, as DCNs de Engenharia (2019) estabeleceram que o desenvolvimento das competências na formação do engenheiro se dá a partir dos seguintes princípios:

- Formular e conceber soluções desejáveis de Engenharia, analisando e compreendendo a necessidade dos usuários e seu contexto;

- Analisar e compreender os fenômenos físicos e químicos por meio de modelos simbólicos, físicos e outros, uma vez verificados e validados por experimentação;

- Conceber, projetar e analisar sistemas, produtos (bens e serviços), componentes ou processos;

- Implantar, supervisionar e controlar as soluções de Engenharia;

- Comunicar-se eficazmente nas formas escrita, oral e gráfica;

- Trabalhar e liderar equipes multidisciplinares;

- Conhecer e aplicar com ética a legislação e os atos normativos no âmbito do exercício da profissão; e

- Aprender de forma autônoma e lidar com situações e contextos complexos, atualizando-se em relação aos avanços da ciência, da tecnologia, bem como em relação aos desafios da inovação.

Além das competências de caráter geral as DCNs de Engenharia (2019) apontam outras competências que devem ser desenvolvidas.

\begin{abstract}
"Além das competências de caráter geral, devem ser definidas as de caráter especifico do curso. Evidentemente que tais competências devem ser desenvolvidas no contexto da habilitação ou ênfase escolhida para o curso. Além disso, o Projeto Pedagógico do Curso (PPC) deve deixar claro como cada competência é desenvolvida e avaliada no curso". (BRASIL, 2019, p. 26).
\end{abstract}

É possível verificar que uma das inovações das DCNs de Engenharia "é a explicitação das possibilidades de atuação do engenheiro tanto como projetista de soluções inovadoras, quanto como empreendedor, em todo o ciclo de vida do produto e do empreendimento". (BRASIL, 2019, p. 26).

\title{
3.2. Foco no desenvolvimento das competências e metodologias inovadoras
}

"A Engenharia não pode mais ser vista como um corpo de conhecimento, ou seja, como algo que os estudantes possam adquirir por meio do estudo do conhecimento técnico, ou não técnico, ou pela mera atividade de cursar e ser aprovado em um número de disciplinas que completem o conteúdo desejado". (MEC, 2019, p. 29).

Conforme DCNs de Engenharia, "A formação em Engenharia deve ser vista principalmente como um processo. Um processo que envolve as pessoas, suas necessidades, suas expectativas, seus comportamentos e que requer empatia, interesse 
pelo usuário". (MEC 2019, p. 29). E a partir da aplicação da tecnologia transformar a observação em formulação do problema a ser resolvido, alcançando o resultado que seja tecnicamente viável e desejável para o usuário final.

No desenvolvimento de competências requer habilidades empreendedoras que consiga engajar e atrair diferentes interessados no alcance dos objetivos.

Para que a estrutura curricular atenda às demandas de formação de engenheiros com competências técnicas são necessárias metodologias de ensino modernas e que se adequem a nova realidade global. Quem busquem ativar a motivação dos alunos, colocando-os ativos na aprendizagem.

É de se destacar o Project Based Learning - PBL, o ensino baseado em projetos. Uma metodologia com vasto desenvolvimento em competências, na aprendizagem colaborativa e na interdisciplinaridade. Abre-se espaço para novas tecnologias digitais como o uso da Sala de Aula Invertida, Laboratório Rotacional e abrindo espaço para o aluno em atividades e ambientes de imersão tecnológica, segundo Brasil (MEC 2019).

O ponto principal é imprimir maior sentido, dinamismo e autonomia ao processo de aprendizagem em Engenharia por meio do engajamento do aluno em atividades práticas, desde o primeiro ano do curso. Assim, o aprendizado baseado em metodologias ativas, a solução dos problemas concretos em atividades, que exijam conhecimentos interdisciplinares, são alguns dos instrumentos que podem ser acionados para elevar a melhoria do ensino e para combater a evasão escolar. (BRASIL, 2019, p. 30).

As DCNs de Engenharia (MEC 2019), pretendem promover a diversidade e induz as políticas de inovação. Provocando os novos engenheiros atenderem distintas demandas: tecnológicas, desenvolvimento de competências de maneira contextualizadas que supram as necessidades das demandas da sociedade.

\section{ANÁLISE COMPARATIVA DO PPC DA EPUSP E AS DCNs DE ENGENHARIA}

É apresentado a seguir um comparativo entre o PPC da EPUSP do curso em análise e as DCNs de Engenharia atuais com o objetivo de verificar quais pontos são correlatos entre as diretrizes e quais são as lacunas que ainda existem, conforme Quadro 1.

Quadro 1 - Comparações entre PPC da EPUSP e as DCNs de Engenharia

\begin{tabular}{|l|l|l|}
\hline & \multicolumn{1}{|c|}{ PPC da EPUSP } & \multicolumn{1}{c|}{$\begin{array}{c}\text { DCNs de Engenharia } \\
\text { CNE/CES No: 1/2019 }\end{array}$} \\
\hline $\begin{array}{l}\text { Característica } \\
\text { predominante }\end{array}$ & Impositiva & Diretiva \\
\hline Áreas de engenharia & $\begin{array}{l}\text { Existem hoje 17 cursos contando as } \\
\text { habilitações e ênfases }\end{array}$ & Em aberto \\
& $\begin{array}{l}\text { Existem hoje 17 cursos contando as } \\
\text { habilitações e ênfases }\end{array}$ & $\begin{array}{l}\text { Existem varias aprovadas pelo } \\
\text { MEC e um numero menor no } \\
\text { sistema CONFEA/CREA }\end{array}$ \\
\hline Perfil do egresso & $\begin{array}{l}\text { Garantir adequada formação } \\
\text { científica, sólida formação em } \\
\text { técnicas da engenharia, etc }\end{array}$ & $\begin{array}{l}\text { Sólida formação voltada para } \\
\text { uma visão sistêmica e holística, } \\
\text { não só do profissional, mas } \\
\text { também do cidadão- } \\
\text { engenheiro, comprometido com } \\
\text { os valores fundamentais da } \\
\text { per sido estimulado a desenvolver umade na qual se insere }\end{array}$ \\
\hline
\end{tabular}




\begin{tabular}{|c|c|c|}
\hline & & $\begin{array}{l}\text { Adquirir habilidades e } \\
\text { competências }\end{array}$ \\
\hline Projeto do curso & $\begin{array}{l}\text { Deixa claro como as atividades } \\
\text { acadêmicas levam a formação do } \\
\text { perfil do profissional }\end{array}$ & $\begin{array}{l}\text { Deixa claro como as atividades } \\
\text { acadêmicas levam a formação } \\
\text { do perfil do profissional }\end{array}$ \\
\hline Organização Curricular & $\begin{array}{l}\text { Flexibilização curricular (optativas e } \\
\text { módulos de outras engenharias, } \\
\text { incluindo pré-mestrados no final no } 5^{\circ} \\
\text { ano) }\end{array}$ & Flexibilização curricular \\
\hline Currículo & $\begin{array}{l}\text { Conforme a Resolução CNE/CES } 11 \\
\text { de 11/03/2002 }\end{array}$ & $\begin{array}{l}\text { Conforme a Resolução } \\
\text { CNE/CES } 11 \text { de } 11 / 03 / 2002 \\
\text { "Conjunto de experiências de } \\
\text { aprendizado, que o estudante } \\
\text { incorpora durante o processo } \\
\text { participativo, de desenvolver } \\
\text { um programa de estudos } \\
\text { coerentemente integrado" }\end{array}$ \\
\hline Foco do currículo & Habilidades e Competências & Habilidades e Competências \\
\hline Projetos integralizadores & $\begin{array}{l}\text { O trabalho de formatura com duração } \\
\text { de } 2 \text { semestres permite fazer projetos } \\
\text { integralizadores }\end{array}$ & $\begin{array}{l}\text { Prevê projetos de } \\
\text { integralização de curso e de } \\
\text { currículos }\end{array}$ \\
\hline Duração do curso & $\begin{array}{l}\text { Duração de todas as habilitações é de } \\
5 \text { anos, permitindo-se um prazo } \\
\text { máximo de } 15 \text { semestres para a } \\
\text { conclusão do curso }\end{array}$ & Não estabelece \\
\hline Estágio & $\begin{array}{l}\text { Obrigatório com no mínimo de } 180 \\
\text { horas }\end{array}$ & $\begin{array}{l}\text { Carga horária do estágio } \\
\text { curricular deve estar prevista no } \\
\text { Projeto Pedagógico do Curso, } \\
\text { sendo a mínima de } 160 \text { (cento } \\
\text { e sessenta) horas }\end{array}$ \\
\hline Metodologias de ensino & $\begin{array}{l}\text { Existem algumas experiências de } \\
\text { disciplinas que utilizam aprendizagem } \\
\text { ativa por projetos e problemas, } \\
\text { utilizando espaços especiais de } \\
\text { aprendizagem com uso de } \\
\text { microprocessadores (Arduino), } \\
\text { impressoras 3D, cortadoras laser, etc } \\
\text { Alguns docentes usam aulas } \\
\text { gravadas e salas de aula invertidas e } \\
\text { aprendizagem por pares }\end{array}$ & $\begin{array}{l}\text { Aponta para que o curso adote } \\
\text { metodologias inovadoras mais } \\
\text { adequadas à nova realidade } \\
\text { global, apontam as } \\
\text { metodologias ativas. } \\
\text { Cita o Project Based Learning- } \\
\text { PBL }\end{array}$ \\
\hline $\begin{array}{l}\text { Foco no processo de } \\
\text { ensino }\end{array}$ & $\begin{array}{l}\text { Migrando aos poucos para um papel } \\
\text { mais centrado no aluno }\end{array}$ & Centrado no Aluno \\
\hline Avaliação & Menciona todos os processos & Menciona todos os processos \\
\hline Instituição de ensino & $\begin{array}{l}\text { Existe um processo de avaliação de } \\
\text { professores e de disciplinas baseado } \\
\text { em questionários aplicados sobre } \\
\text { cada disciplina nas turmas e discutida } \\
\text { em comissões de alunos e } \\
\text { professores } \\
\text { Existe um programa de acolhimento } \\
\text { pedagógico organizado pelo grêmio } \\
\text { de alunos e um psíquico e econômico } \\
\text { e pela escola }\end{array}$ & $\begin{array}{l}\text { Acompanhamento ativo da } \\
\text { aprendizagem do aluno } \\
\text { Acompanhamento e } \\
\text { acolhimento como estratégia } \\
\text { contra a evasão }\end{array}$ \\
\hline Papel do Aluno & $\begin{array}{l}\text { Migrando aos poucos para um papel } \\
\text { mais ativo }\end{array}$ & ente Ativo \\
\hline
\end{tabular}

Fonte: Os autores com base no PPC da EPUSP e nas DCNs de Engenharia 


\section{1. $\quad$ Análise do perfil do egresso e competências esperadas}

Para uma melhor visualização do perfil do egresso é apresentado uma análise entre o PPC da EPUSP do curso em análise e as DCNs de Engenharia para verificar quais pontos são correlatos e não correlatos entre eles, conforme Quadro 2.

Quadro 2 - Comparações do Perfil do Egresso

entre PPC da EPUSP e as DCNs de Engenharia

\begin{tabular}{|c|c|}
\hline PPC da EPUSP & $\begin{array}{l}\text { DCNs de Engenharia } \\
\text { CNE/CES №: } 1 / 2019\end{array}$ \\
\hline $\begin{array}{l}\text { Adequada formação científica e sólida formação em } \\
\text { técnicas da engenharia }\end{array}$ & Visão sistêmica e holística de formação \\
\hline $\begin{array}{l}\text { Agente da evolução econômica e social e consciente } \\
\text { para desenvolver uma conduta profissional ética }\end{array}$ & $\begin{array}{l}\text { Comprometido com os valores } \\
\text { fundamentais da sociedade na qual se } \\
\text { insere }\end{array}$ \\
\hline $\begin{array}{l}\text { Ter capacidade de planejar e ser objetivo no } \\
\text { estabelecimento de metas, de elaborar soluções } \\
\text { técnica e economicamente competitivas, de } \\
\text { supervisionar e de coordenar projetos de Engenharia }\end{array}$ & $\begin{array}{l}\text { Formular e conceber soluções desejáveis } \\
\text { de Engenharia, analisando e } \\
\text { compreendendo a necessidade dos } \\
\text { usuários e seu contexto }\end{array}$ \\
\hline Ter capacidade de operar e manter sistemas & $\begin{array}{l}\text { Analisar e compreender os fenômenos } \\
\text { físicos e químicos por meio de modelos } \\
\text { simbólicos, físicos e outros, uma vez } \\
\text { verificados e validados por } \\
\text { experimentação }\end{array}$ \\
\hline $\begin{array}{l}\text { Ter capacidade de conceber e analisar sistemas, } \\
\text { produtos e processos }\end{array}$ & $\begin{array}{l}\text { Conceber, projetar e analisar sistemas, } \\
\text { produtos (bens e serviços), componentes } \\
\text { ou processos }\end{array}$ \\
\hline $\begin{array}{l}\text { Ter visão crítica de ordem de grandeza na solução e } \\
\text { interpretação de resultados de engenharia }\end{array}$ & $\begin{array}{l}\text { Implantar, supervisionar e controlar as } \\
\text { soluções de Engenharia }\end{array}$ \\
\hline $\begin{array}{l}\text { Ter a capacidade de comunicar oralmente e de } \\
\text { registrar, de forma ética, seu conhecimento, tanto em } \\
\text { português como em pelo menos uma língua } \\
\text { estrangeira, preferencialmente o inglês }\end{array}$ & $\begin{array}{l}\text { Comunicar-se eficazmente nas formas } \\
\text { escrita, oral e gráfica }\end{array}$ \\
\hline Ter capacidade de liderança para trabalhar em equipe & $\begin{array}{l}\text { Trabalhar e liderar equipes } \\
\text { multidisciplinares }\end{array}$ \\
\hline $\begin{array}{l}\text { A USP tem um manual de Ética e a EPUSP criou uma } \\
\text { comissão de Ética }\end{array}$ & $\begin{array}{l}\text { Conhecer e aplicar com ética a legislação } \\
\text { e os atos normativos no âmbito do } \\
\text { exercício da profissão }\end{array}$ \\
\hline $\begin{array}{l}\text { Em algumas disciplinas e no trabalho de formatura o } \\
\text { aluno se espera que o aluno tenha uma certa } \\
\text { autonomia e que trabalhe com problemas complexos e } \\
\text { multidisciplinares }\end{array}$ & $\begin{array}{l}\text { Aprender de forma autônoma e lidar com } \\
\text { situações e contextos complexos, } \\
\text { atualizando-se em relação aos avanços } \\
\text { da ciência, da tecnologia, bem como em } \\
\text { relação aos desafios da inovação }\end{array}$ \\
\hline $\begin{array}{l}\text { - Ter iniciativa e criatividade para tomada de decisões. } \\
\text { - Ter visão clara do papel de cliente, produtor, } \\
\text { fornecedor e consumidor } \\
\text { - Saber bem usar as ferramentas básicas da } \\
\text { informática }\end{array}$ & $\begin{array}{l}\text { A iniciativa e criatividade é incentivada } \\
\text { em todas disciplinas de projetos. } \\
\text { Muitas disciplinas exploram conceitos } \\
\text { sobre as cadeias produtivas em várias } \\
\text { áreas de atuação da engenharia } \\
\text { Existe uma disciplina básica de } \\
\text { introdução a computação e varias } \\
\text { disciplinas que incentivam o uso de } \\
\text { programas específicos para realizar } \\
\text { estudos e analises e o uso de } \\
\text { programação para simulação é constante }\end{array}$ \\
\hline $\begin{array}{l}\text { - Ter compromisso com a qualidade do que faz } \\
\text { - Ter compromisso com a ética profissional } \\
\text { - Ter responsabilidade social, política e ambiental } \\
\text { - Ter postura proativa e empreendedora }\end{array}$ & $\begin{array}{l}\text { O compromisso com a qualidade dos } \\
\text { trabalhos é incentivado em todas as } \\
\text { produções e entregas de trabalhos nas } \\
\text { disciplinas }\end{array}$ \\
\hline
\end{tabular}




\begin{tabular}{|l|l|}
\hline - Ter compreensão da necessidade da permanente & Todos cursos têm uma disciplina que \\
busca de atualização profissional & discute impactos ambientais e sociais da \\
engenharia & Algumas disciplinas discutem estudos de \\
& caso com foco na Ética \\
& Existem disciplinas de projeto que \\
& desenvolvem projetos inovadores sobre \\
& problemas reais das empresas. \\
& A Epusp tem um Programa de Educação \\
& Continuada - PECE que permite alunos \\
& de graduação cursar disciplinas \\
\hline
\end{tabular}

Fonte: Os autores com base no PPC da EPUSP e nas DCNs de Engenharia - Perfil do Egresso

\section{Considerações FINAIS}

O trabalho apresentou análise crítica do PPC do curso de engenharia elétrica com ênfase em Energia e Automação Elétricas da EPUSP em relação ao novo texto das DCNs de Engenharia aprovados em 2019.

Alguns itens são compatíveis com as diretrizes apresentadas nas DCNs de Engenharia e outros pontos deverão sofrer adaptações e correções. Um dos itens que deve ser implementado é a explicitação de como serão desenvolvidas e avaliadas as competências para atingir o perfil esperado do formando. Outro item que deve ser reforçado está ligado aos sistemas de acolhimento econômico e psicopedagógico dos alunos devido principalmente a mudança de parte do perfil do aluno ingressante através das cotas para alunos oriundos de escolas públicas e PPI que devem atingir $50 \%$ das vagas para o ano de 2021.

O processo de avaliação continuada deve evoluir com a criação de novas ferramentas baseadas em indicadores e metas definidas. As criações de formas de contabilização de atividades extras curriculares de alunos como atividades em grupo de extensão estão sendo implementadas. Programas para aumentar formas de relação entre a universidade e as empresas estão em andamento. $O$ uso de aprendizagem ativa em disciplinas está se expandindo dentro da escola inclusive com a criação de espaços apropriados para isto como o Inovalab e projetos de inovadores de PPC como o financiado pela Capes/Fullbright para o curso de engenharia Química da EPUSP serão implementados e usados nos diversos cursos da escola. A escola tem um grupo que pesquisa em educação em engenharia (POLIEdu) e tem realizado eventos para discutir o tema coma participação de pesquisadores de instituições de ensino de engenharia dos EUA e Europa. Cursos de Capacitação docente tem ocorrido na escola e a USP criou um canal de comunicação com seus ex-alunos da EPUSP tem uma Associação de Engenheiros Formados - AEP, a mais antiga do país que dá apoio com diversos programas a escola e a alunos e recentemente foi criado um fundo de endowment que financia projetos de alunos e de docentes.

\section{Agradecimentos}

Agradecemos também ao Grupo de Pesquisas POLIEdu (Grupo de Pesquisa em Educação de Engenharia da Escola Politécnica da USP), ao qual pertencemos, pelo apoio sólido nas pesquisas. 


\title{
REFERÊNCIAS
}

MEC. Portaria 011/2002 do CNE/CES, Diretrizes Curriculares Nacionais dos Cursos de Engenharia. Disponível em:

<http://portal.mec.gov.br/cne/arquivos/pdf/CES112002.pdf>. Acesso em: 1 mar. 2021.

\section{MEC. Portaria 01/2019 do CNE/CES, Diretrizes Curriculares Nacionais dos Cursos} de Engenharia. Disponível em:

<http://portal.mec.gov.br/index.php?option=com_docman\&view=download\&alias=109871pces001-19-1\&category_slug=marco-2019-pdf\&ltemid=30192>. Acesso em: 1 mar. 2021.

PEA. Projeto Político Pedagógico: Engenharia Elétrica Ênfase Energia e Automação Estrutura Curricular 3 - EC-3. Escola Politécnica da Universidade de São Paulo - EPUSP. Disponível em: < http://www.pea.usp.br/wp-content/uploads/sites/21/2017/08/PPP-EC32017-PEA_v16agosto2017.pdf>. Acesso em: 1 jun. 2020.

\section{ANALYSIS OF THE ADEQUACY OF THE PEDAGOGICAL PROJECT FOR THE ELECTRICAL ENGINEERING COURSE IN FRONT OF THE NEW CURRICULAR ENGINEERING GUIDELINES}

\begin{abstract}
This article presents an analysis of the pedagogical project of the electrical engineering course with an emphasis on electrical energy and automation about the new engineering curriculum guidelines approved in April 2019. The analysis was made by comparing the minimum items proposed in the guidelines and in the items proposed in the pedagogical project of the course in a critical way aiming to detect points met and incomplete points, and that needs a review and readjustment. The new guidelines promulgated by the Ministry of Education - MEC, such as those of 2002, are centered on the development of competence and require that pedagogical projects explain how they are developed and reinforced and how they are evaluated during the course in the subjects. There is a strong incentive to use new teaching and learning situations and the use of appropriate environments that favor active strategies, where students are the center of the process. The greater interaction of the university with society and its various agents, such as the government in its various instances, with companies, NGOs are encouraged in offering internships and in the proposal to bring real-world problems to debate and search for solutions. The minimum number of internship hours of 180 hours and the requirement for a final course project was also maintained in these new guidelines. As a conclusion of the work, proposals for alteration in the pedagogical project of the course are discussed to adapt it to the new guidelines of the engineering course.
\end{abstract}

Keywords: Pedagogical Course Project, National Curriculum Guidelines, Engineering, Competency-based teaching. 